\title{
Canadian Helicobacter Study Group Consensus Conference: Update on the management of Helicobacter pylori - An evidence-based evaluation of six topics relevant to clinical outcomes in patients evaluated for $H$ pylori infection
}

\author{
Richard Hunt $\mathrm{MD}^{1 *}$, Carlo Fallone $\mathrm{MD}^{2 *}$, Sander Veldhuyzan van Zanten $\mathrm{MD}^{3 *}$, Phil Sherman $\mathrm{MD}^{4 *}$, \\ Fiona Smaill $\mathrm{PhD}^{1 *}$, Nigel Flook $\mathrm{MD}^{5 *}$, Alan Thomson MD $\mathrm{PhD}^{5 *}$, and all participants of CHSG $2004^{\dagger}$
}

\begin{abstract}
R Hunt, C Fallone, S Veldhuyzan van Zanten, et al. Canadian Helicobacter Study Group Consensus Conference: Update on the management of Helicobacter pylori - An evidence-based evaluation of six topics relevant to clinical outcomes in patients evaluated for $H$ pylori infection. Can J Gastroenterol 2004;18(9):547-554.
\end{abstract}

\begin{abstract}
As an update to previously published recommendations for the management of Helicobacter pylori infection, an evidence-based appraisal of six topics was undertaken in a consensus conference sponsored by the Canadian Helicobacter Study Group. The issues addressed and recommendations made were: bismuth-containing quadruple therapy is appropriate as an alternative first-line eradication strategy for $\mathrm{H}$ pylori infection; searching for and treating $\mathrm{H}$ pylori infection is warranted in patients considered to be at high risk for gastric cancer; $\mathrm{H}$ pylori infection should be eradicated before initiating long-term treatment with nonsteroidal anti-inflammatory drugs or acetylsalicylic acid; the stool antigen test has a limited role in the diagnosis of $\mathrm{H}$ pylori infection; the benefits of $\mathrm{H}$ pylori eradication in patients on long-term proton pump inhibitor therapy are not sufficient to warrant recommending a strategy of searching for and eradicating the infection among these patients; and a strategy of 'test and eradicate' for $H$ pylori infection in patients with uninvestigated dyspepsia is costeffective in Canada relative to a trial of proton pump inhibitor therapy. The goal was to establish guidelines on the best evidence using the same structure to address and formulate recommendations for each issue. The degree of consensus for each issue is presented.
\end{abstract}

Key Words: Investigation and treatment of $\mathrm{H}$ pylori infections
Conférence consensuelle du GÉCHP : Le point sur la prise en charge de Helicobacter pylori - Analyse formelle de six grands thèmes relatifs au traitement des patients examinés pour infection à $H$. pylori

Une conférence consensuelle réalisée sous l'égide du Groupe d'études canadien sur Helicobacter pylori a permis de mettre à jour les recommandations existantes relativement à la prise en charge de Helicobacter pylori dans le cadre d'une analyse de six grands thèmes étayés par des preuves formelles. Les enjeux visés et les recommandations formulées sont les suivants : la quadruple thérapie avec bismuth constitue une autre stratégie d'éradication de première intention envisageable pour $H$. pylori; le dépistage et le traitement de l'infection à $H$. pylori sont justifiés chez les patients jugés à risque élevé à l'égard du cancer de l'estomac; l'infection à H. pylori doit être éradiquée avant l'instauration d'un traitement prolongé par anti-inflammatoires non stéroïdiens ou acide acétylsalicylique; la recherche d'antigènes dans les selles a un rôle restreint dans le diagnostic de l'infection à $H$. pylori; les avantages de l'éradication de $H$. pylori chez les patients sous traitement prolongé par inhibiteurs de la pompe à protons ne justifient pas l'application d'une stratégie de dépistage et d'éradication de l'infection chez ces patients, et dans le contexte canadien, la stratégie qui consiste à « dépister et éradiquer » l'infection à H. pylori chez les patients souffrant d'une dyspepsie non investiguée est économique comparativement à l'essai d'un traitement par inhibiteurs de la pompe à protons. L'objectif était de mettre à jour les directives fondées sur les preuves les plus concluantes à partir de la même structure, afin de formuler des recommandations pour chacun des thèmes retenus. Le degré de consensus obtenu pour chaque recommandation est également présenté.

\section{RATIONALE FOR UPDATE OF GUIDELINES} Given the progress in defining the relationship between Helicobacter pylori infection and the human host, it is imperative to periodically revisit and reassess whether new information offers opportunities to improve patient care. The first consensus conference of the Canadian Helicobacter Study Group (CHSG) was held in 1997, and resulted in published recommendations in
1998 (1). Subsequent consensus meetings of the CHSG have led to four further publications: a first update of the initial recommendations in 1999 (2); recommendations on the management of $\mathrm{H}$ pylori infection in children and adolescents in 1999 (3); a review of the effect of antibiotic resistance on treatment choices in 2000 (4); and an analysis of the relationship between $H$ pylori infection and dyspepsia in 2002 (5).

*Canadian Helicobacter Study Group; †Participants listed at the end of the paper

${ }^{1}$ McMaster University, Hamilton, Ontario; ${ }^{2} \mathrm{McGill}$ University Health Centre, Montreal, Quebec; ${ }^{3}$ Dalhousie University, Halifax, Nova Scotia;

${ }^{4}$ The Hospital for Sick Children, Toronto, Ontario; ${ }^{5}$ University of Alberta, Edmonton, Alberta

Correspondence: Dr ABR Thomson, Division of Gastroenterology, University of Alberta, \#205 College Plaza, 8215-112 Street, Edmonton,

Alberta T6G 2C8. Telephone 780-492-6490, fax 780-492-7964, e-mail alan.thomson@ualberta.ca

Received for publication February 5, 2004. Accepted July 8, 2004 


\section{TABLE 1}

Quality of evidence

I At least one appropriately designed, randomized controlled trial

II-1 At least one appropriately designed controlled trial without randomization

II-2 Cohort or case-controlled studies, preferably from one or more research groups

II-3 Substantial or marked results from uncontrolled studies

III Opinions of experts based on clinical experience or descriptive studies

\section{TABLE 2}

\section{Classification of recommendations}

\begin{tabular}{ll} 
A & Good supportive evidence \\
B & Fair supportive evidence \\
C & Poor supportive evidence but recommendations reasonable \\
& on other grounds \\
D & Fair contrary evidence \\
E & Good contrary evidence \\
\hline
\end{tabular}

In the most recent consensus conference in 2003, specific issues were addressed to recognize accumulating data in areas that have the potential to alter current practice. For each issue, relevant data were critically appraised and ranked by quality. The discussion of the relevance and implications of these data provided the basis for formulating a specific recommendation. The consensus group was polled three times for each of the six recommendations, using a predefined rating system. The participants were polled on the quality of available data, the strength of the data supporting the specific recommendation and the wording of the recommendation itself. Similar methods to form consensus on clinical recommendations have been employed previously $(6,7)$.

In the 20 years since $H$ pylori was first cultured from the human stomach and found to be an important cause of gastroduodenal diseases (8), the relationship between this bacterium and the gastrointestinal tract has proven to be surprisingly complex. Although $H$ pylori is a well described pathogen for peptic ulcer disease (9) and mucosa-associated lymphoid tissue lymphoma (10), and a designated cocarcinogen for gastric cancer (11), the magnitude of the risks to the health status of most infected individuals is low. The costs and varying estimates of benefits and risks of a population-based 'search and treat' strategy have created the need for individual recommendations for specific population subgroups. The recommendations in the present publication complement and extend those previously endorsed by the CHSG.

\section{CONSENSUS CONFERENCE STRUCTURE}

The CHSG consensus conference was convened specifically to address six issues relevant to the diagnosis and treatment of patients with $\mathrm{H}$ pylori infection. These issues were selected either because they had not been comprehensively addressed in previous consensus meetings, or because new information suggested that modifications in these areas had the potential to change management and to improve health outcomes. The consensus conference was held May 30 to June 1, 2003 in
TABLE 3

Voting on recommendations

\begin{tabular}{ll}
\hline A & Accept completely \\
B & Accept with some reservation \\
C & Accept with major reservation \\
D & Reject with reservation \\
E & Reject completely
\end{tabular}

E Reject completely

Ottawa, Ontario. As in past consensus conferences, broad interest groups were represented with expertise in adult and pediatric gastroenterology, infectious diseases, microbiology, primary care medicine, pharmacology, epidemiology and the basic sciences.

The consensus conference was sponsored by the CHSG, the Canadian Association of Gastroenterology, the Canadian Digestive Health Foundation and CanGut. Major financial support for the conference was provided through equal unrestricted educational grants from Altana Pharma Inc/Solvay Pharma Inc, AstraZeneca Canada Inc, Axcan Pharma Inc and Janssen-Ortho Inc. Representatives from the pharmaceutical industry were invited to attend and participate in the discussions, but did not vote on the consensus recommendations. None of the participants were remunerated for their participation in the consensus meeting.

\section{CONSENSUS CONFERENCE PROCESSES}

Each of the six topics chosen for evaluation and the formulation of clinical recommendations was addressed independently. Selected papers relevant to the topics to be discussed were circulated in advance. An overview of each issue based on comprehensive literature searches was presented. This was followed by a period of discussion, in which the existing data were evaluated and critiqued. At the end of this discussion, a recommendation with specific wording was formulated. Once an acceptable recommendation based on available evidence was established, formal voting was undertaken for three issues. In order, these were: the quality of the evidence (Table 1); the classification of the evidence relative to the recommendation being made (Table 2 ); and the recommendation itself (Table 3). In the present summary, this order has been altered to place the vote on the recommendation first, followed by tallies of the votes on the quality of evidence and the classification of evidence supporting the recommendation.

Each section starts with the consensus recommendation. Thus, readers of the document can familiarize themselves quickly with the major conclusions. However, the relevance of these recommendations to individual patient care is best interpreted by also reviewing the quality of the data on which the recommendations are based, the degree of consensus among the participating experts, and the reservations and amplifications contained in the discussion sections. Unanimous votes were uncommon. However, it is important to emphasize that the basic premise of each recommendation was uniformly accepted, with the exception of the vote on deeming eradication of $\mathrm{H}$ pylori infection to be unnecessary before initiating long-term therapy with a proton pump inhibitor (PPI). Each of the recommendations addressed in this update of the treatment guidelines is designed to have immediate practical clinical application. 


\section{RECOMMENDATION 1}

A quadruple combination of a PPI, bismuth, tetracycline and metronidazole for 10 to 14 days can be considered first-line therapy for the eradication of $\mathrm{H}$ pylori.

Summary of vote on recommendation

- $A=34$

- $\mathrm{B}=22$

- $\mathrm{C}=4$

- $\mathrm{D}, \mathrm{E}=0$

Summary of vote on level of evidence

- Level I=4

- Levels II to III=0

Summary of vote on data supportive of the recommendation

- $A=28$

- $\mathrm{B}=3$

- $\mathrm{C}, \mathrm{D}, \mathrm{E}=0$

\section{Discussion of recommendation 1}

Multiple controlled trials confirm that quadruple therapy given for 10 to 14 days is both effective and safe for the eradication of H pylori infection $(12,13)$. Quadruple therapy meets the criterion previously employed by CHSG (greater than $80 \%$ efficacy on an intent-to-treat basis in a controlled trial) to be identified as 'recommended' as a first-line therapy. Previously, it was designated a 'rescue' regimen rather than a first-line eradication strategy, due to the perception that it was complex and less well tolerated than PPI triple therapies (14,15, unpublished data). Neither of these concerns was an issue in recent trials (16).

Some concern was expressed about the inability of controlled trials to adequately emulate routine clinical care. Although quadruple therapy may be at least as effective as PPI-based triple therapy when compliance is comparable, the fact that compliance is inversely related to the complexity of a given therapy provides a basis for characterizing the greater demands of a quadruple therapy as a relative liability. Compliance with treatment regimens is an important determinant of successful eradication (17). However, a recent meta-analysis concluded that PPI-based triple therapies and quadruple therapy were roughly equivalent, not only in effectiveness but also in compliance and side effect profile (12). Those who expressed reservations about the recommendation suggested without any evidence that quadruple and PPI-based triple therapies should probably not be considered equivalent from a practical perspective.

The relative efficacy of different dosing schemes with quadruple therapy regimens is not well defined. The quadruple therapy recommended for consideration as first-line therapy by the consensus panel was standard dose of PPI twice daily, $375 \mathrm{mg}$ or $500 \mathrm{mg}$ of metronidazole four times daily, $375 \mathrm{mg}$ or $500 \mathrm{mg}$ of tetracycline four times daily, and $262 \mathrm{mg}$ of bismuth subsalicylate (two tablets of Pepto-Bismol, Procter \& Gamble, USA) four times per day. It was thought that giving metronidazole three times daily while all other medications were taken four times daily could lead to confusion. This recommendation was based on the premise of simplicity and evidence of superior efficacy, which includes three-times-daily dosing and once-daily dosing of the PPI. The recommended duration of quadruple therapy is 10 to 14 days.

The 10 to 14 days of a quadruple therapy regimen is longer than the seven to 10 days currently recommended for PPIbased triple therapy, although a recent meta-analysis suggests that 14-day PPI-based triple therapy achieves better results than seven-day schedules $(18,19)$. A longer duration was chosen because it was associated with a greater cure rate. Indeed, there are substantial data, particularly from studies in North America, to suggest that PPI-based triple therapies are also more effective if administered over 14 rather than seven days $(17,18)$, although the increase in benefits is small $(5 \%$ to $7 \%$ [18]). On the other hand, the recent large study by Vakil et al (20) in 803 patients did not show any difference between sevenand 10-day rabeprazole triple therapy with clarithromycin and amoxycillin.

Resistance to the antibiotics contained in any eradication regimen affects the treatment success of triple therapies, and to a lesser extent quadruple therapies (unpublished data). In areas where the prevalence of resistant strains of $H$ pylori is known, antibiotics should be selected accordingly. Unfortunately, there is a paucity of data on prevalence of antibiotic resistance to $H$ pylori in Canada. The most recent Canadian data suggest that resistance to metronidazole is stable, around $20 \%$. Resistance to clarithromycin may have risen from $2 \%$ to $8 \%$, and resistance to amoxycillin is rare; less than $1 \%$ of the population are resistant to amoxycillin (21). In patients who fail a first-line therapy, susceptibility testing should be considered to guide selection of the second treatment regimen.

In summary, there is level I evidence that quadruple therapy is effective and well tolerated for the eradication of $\mathrm{H}$ pylori infection. Eradication rates with the recommended quadruple therapy are comparable with those achieved with PPI-based triple therapy regimens in patients who adhere to the protocol (12). Given the lower number of tablets and twice daily dosing, in practice, PPI-based triple therapy may be the first choice.

\section{RECOMMENDATION 2}

Asymptomatic individuals with a first degree relative with a history of gastric cancer or coming from an ethnic or geographic background associated with a high risk of gastric cancer, or patients undergoing resection for early gastric cancer, should be considered for a 'search and treat' strategy for H pylori infection.

Summary of vote on recommendation

- $A=1$

- $\mathrm{B}=23$

- $\mathrm{C}=7$

- $\mathrm{D}, \mathrm{E}=0$

Summary of vote on level of evidence

- I, II-1=0

- II $-2=2$

- $\mathrm{II}-3=30$

- $\mathrm{III}=0$ 
Summary of vote on data supportive of the recommendation

- $\mathrm{A}=0$

- $\mathrm{B}=10$

- $\mathrm{C}=26$

- $\mathrm{D}, \mathrm{E}=0$

\section{Discussion of recommendation 2}

There is a well-established epidemiological association between $H$ pylori infection and an increased risk of gastric cancer (22). The World Health Organization has identified H pylori as a class I carcinogen. The odds ratio for developing gastric cancer in an individual infected with $\mathrm{H}$ pylori, relative to someone who is uninfected, has been variably estimated between 1.6- and fourfold overall in general population surveys, and up to 13-fold when cofactors, such as the virulence characteristics of $H$ pylori strains and the age of the patient, are considered (23).

Pathophysiological changes induced by $\mathrm{H}$ pylori colonizing the gastric mucosa are a plausible explanation for its increased risk of development of malignancy. Invariably, $H$ pylori infection induces gastritis, which in some patients progresses to atrophy, intestinal metaplasia and dysplasia. The potential for metaplasia to progress to malignancy has been described repeatedly (24). Eradication of $H$ pylori infection reverses the progression of gastric glandular atrophy (25).

Due to the slow and unpredictable progression from gastritis to malignancy, and the considerable logistical constraints, prospective randomized trials to provide definitive evidence that eradication of $\mathrm{H}$ pylori infection reduces the risk of gastric cancer are not yet available. In nonrandomized cohort trials of infected patients, protection against the development of gastric cancer has been observed with eradication of $H$ pylori infection. In a large study of 1246 men in Japan, there were no gastric cancers found in patients over a mean of 7.8 years in $H$ pylori-uninfected patients; in contrast, there was a $2.9 \%$ incidence of gastric cancer in those with $H$ pylori infection (26). In another, much smaller cohort study ( $n=64)$ (27) conducted in Asia, the incidence of cancer was $12 \%$ in those with untreated $H$ pylori infection and gastric adenoma compared with $0 \%$ in those whose infection was successfully eradicated.

In Canada, gastric cancer remains an uncommon malignancy, but the prevalence is higher among several defined population subgroups, particularly aboriginals and immigrants from Asian countries and some European and South American countries where the incidence of this malignancy is high (28). The proposal to look for and eradicate $H$ pylori infection to lessen gastric cancer risk in selected individuals and groups is intuitively attractive, even in the absence of definitive, randomized controlled trial evidence of benefit.

There are theoretical arguments against the recommendation to 'search and treat' for $\mathrm{H}$ pylori infection in groups at high risk for gastric cancer. Cure of $H$ pylori infection slows progression, but may not completely reverse the gastric atrophy or intestinal metaplasia (29). As a result, the eradication of $\mathrm{H}$ pylori infection after these changes have occurred may be too late to prevent progression toward gastric cancer (30). Moreover, other cofactors for malignancy, such as genetic predisposition or dietary factors, may be more important than cure of $\mathrm{H}$ pylori infection.

The optimal age for screening for $H$ pylori infection in this context is also unknown. The CHSG has recommended that, if screening is to be done, it should be performed during late adolescence or early adulthood due to the increased risk of reinfection in childhood (31). Gastric cancer in young individuals is exceedingly rare. Urea breath tests (UBT) are preferred for diagnosis. Serological tests to detect H pylori infection are still acceptable, although it is noted that the false positive rate of serology in persons younger than 40 years of age may be $30 \%$ (32).

There is a marked disparity between consensus support for this recommendation and the quality of the corroborative evidence. Although weakly supported by prospective data, the potential for $\mathrm{H}$ pylori eradication to prevent a life-threatening disease in high-risk individuals is balanced against a low risk of complications from treatment.

Apart from the potential downside of increasing antibiotic resistance, not only to $H$ pylori but also to other bacteria, the risks of treating high-risk individuals are low. There may be additional benefits, such as protection against other known outcomes including peptic ulcers, and perhaps dyspepsia. A proactive position in the presence of compelling theoretical benefits was judged to be warranted, while awaiting more definitive data.

\section{RECOMMENDATION 3A}

Patients initiating long-term nonsteroidal anti-inflammatory drug (NSAID) therapy should be tested for $\mathrm{H}$ pylori infection and treated if positive.

Summary of vote on recommendation

- $\mathrm{A}=11$

- $\mathrm{B}=21$

- $\mathrm{C}, \mathrm{D}, \mathrm{E}=\mathrm{O}$

\section{Summary of vote on level of evidence} - $\mathrm{I}=0$

- $\mathrm{II}-1=27$

- II-2, II-3, III=0

Summary of vote of data supportive of the recommendation - $\mathrm{A}=7$

- $\mathrm{B}=22$

- $\mathrm{C}, \mathrm{D}, \mathrm{E}=\mathrm{O}$

\section{RECOMMENDATION 3B}

Patients initiating long-term acetylsalicylic acid (ASA) prophylaxis for cardiovascular disease should be tested for $\mathrm{H}$ pylori infection and treated if positive.

Summary of vote on recommendation

- $\mathrm{A}, \mathrm{B}=0$

- $\mathrm{C}=29$

- $\mathrm{D}, \mathrm{E}=\mathrm{O}$

Summary of vote on level of evidence

- I, II-1, II-2, II-3=0

- $\mathrm{III}=29$ 
Summary of vote on data supportive of the recommendation

- $\mathrm{A}, \mathrm{B}=0$

- $\mathrm{C}=29$

- $\mathrm{D}, \mathrm{E}=0$

Discussion of recommendations $3 \mathrm{~A}$ and $3 \mathrm{~B}$

Both NSAID- and ASA-induced ulcer complications are associated with substantial rates of morbidity and mortality (23). The risk of a serious gastrointestinal hemorrhage appears to be concentrated particularly in the elderly, or in patients with a previous history of upper gastrointestinal tract hemorrhage (27). NSAID therapy and H pylori infection are independent risk factors for peptic ulcers. In a meta-analysis evaluating their interaction, each increased the risk of ulcer by approximately sixfold, but together increased risk by more than 16 -fold (33). The relative risks posed by NSAIDs and $H$ pylori infection for ulcer complications have been less well studied. In a retrospective analysis of studies of gastroprotective agents to prevent NSAIDinduced ulcers (34), the absence of $H$ pylori infection was associated with a lower risk of developing NSAID-induced ulcers. Eradication of $\mathrm{H}$ pylori before starting NSAID therapy has been associated with a significant reduction in subsequent ulcers (35). Whether the reduction in NSAIDinduced ulcers following $\mathrm{H}$ pylori eradication also reduces the risk of NSAID-induced complications has not yet been demonstrated, although such a benefit is a reasonable expectation. While a comparable interaction between ASA and $H$ pylori is plausible, the only prospective trial conducted so far failed to associate $H$ pylori eradication with a reduction in ASA-induced ulcers (36).

The risk of an NSAID- or ASA-induced gastrointestinal complication, with or without coexisting $H$ pylori infection, is dependent on the underlying risk, which is defined by patient age, previous history of ulcer, ulcer complications, use of other medications (eg, anticoagulants, corticosteroids) and coexisting disease. Approximately $80 \%$ of NSAID-induced complications occur in patients over the age of 65 years (30), but this simply may reflect age-related patterns of prescribing of NSAID therapy. The relative benefit of prophylactic management, including eradication of $H$ pylori infection or concomitant therapy with a gastroprotective agent, will most likely be achieved in those individuals who are at greatest risk.

The eradication of $H$ pylori infection in patients initiating long-term NSAID therapy eliminates a cofactor for ulcer and complications, but NSAIDs alone are sufficient to cause a serious upper gastrointestinal hemorrhage. Certainly in patients who are at high risk because of a previous history of ulcers or their complications, $H$ pylori eradication alone is insufficient and additional risk reduction strategies are essential. This would include prophylaxis with a gastroprotective agent, switching the patient from a conventional NSAID to a cycloxooxygenase-2 inhibitor (coxib), or in those at greatest risk, employing both a coxib and a gastroprotective agent. It should be mentioned that there are currently no clinical trial data which indicate that switching a patient who develops dyspepsia while on a conventional NSAID to a coxib will result in improved symptoms or reduced gastrointestinal complications. The expectation is that this is the case, as coxibs have a lower risk for gastrointestinal complications than conventional NSAIDs.

In persons with limited expected benefit from ASA or NSAIDs, the risk of gastroduodenal complications may outweigh the indications for their use. This includes the use of low-dose ASA for cardioprotection in individuals without identifiable risk factors for cardiovascular disease. Even lowdose ASA is associated with a substantial increase in bleeding complications. While an improvement in the quality of life afforded by NSAIDs in patients with arthritic disease generally warrants this therapy, the risk of gastrointestinal complications should be modified with test and treat strategies for $\mathrm{H}$ pylori infection, and by cotherapy with gastroprotective agents in high-risk groups who are starting ASA or NSAID therapy. Therapy for $H$ pylori infection should also be undertaken in persons who develop ulcers while taking these medications.

The relative protection against ulcers provided by $\mathrm{H}$ pylori eradication may not be predictive of relative protection against ulcer complications. The evidence that prophylactic strategies are effective for primary prevention of new ulcers is a reassuring surrogate for benefit, but should not be confused with definitive evidence of protection against complications, which is the goal of prophylaxis. The rationale for recommending $\mathrm{H}$ pylori eradication to reduce the risk of NSAIDinduced ulcers is stronger for secondary prevention (ie, applying it to patients who have had an NSAID complication) than for primary prevention. However, it should be acknowledged that there is no definitive evidence for either recommendation.

NSAIDs continue to be a major source of morbidity and mortality in most Western countries, including Canada, with an increasing proportion of patients in the older age group where the use of these medications is common. H pylori infection is associated with compromised gastric defenses and, hence, eradication of this pathogen may play an important role in reducing the risks associated with NSAID treatment. Data to confirm and quantify this benefit are needed, but there is a consensus that the clinical evidence to recommend eradication of the infection in patients at high risk of NSAID-induced complications is sufficient to apply to clinical practice.

\section{RECOMMENDATION 4}

There is currently insufficient evidence to consider stool antigen tests an acceptable tool for the diagnosis of $\mathrm{H}$ pylori infection in community-based practice.

\section{Summary of vote on recommendation}

- $A=29$

- $\mathrm{B}=2$

- $\mathrm{C}, \mathrm{D}, \mathrm{E}=\mathrm{O}$

Summary of vote on level of evidence

- I, II-1, II-2=0

- II-3=29

- $\mathrm{III}=0$ 
Summary of vote on data supportive of the recommendation

- $\mathrm{A}=10$

- $\mathrm{B}=20$

- $\mathrm{C}, \mathrm{D}, \mathrm{E}=\mathrm{O}$

\section{Discussion of recommendation 4}

Since the previous CHSG recommendations, the stool antigen test has been introduced as a potential diagnostic method of active $H$ pylori infection. The recently updated European guidelines have accepted the stool antigen test as an alternative to the UBT (36), the diagnostic test of first choice in Europe and Canada. The studies focused mainly on the HpSA test (Meridian Diagnostics, USA). The basis for the rejection of this diagnostic approach at this CHSG meeting was the lack of data about its accuracy in community-based settings. Also, the test requires dedicated and experienced laboratory personnel to be properly performed.

When the stool antigen test is performed appropriately, the rates of both sensitivity and specificity exceed 90\% (37). However, the test is labour-intensive, requires the use of concurrent controls, and appears to be less sensitive and specific when performed outside clinical trials. Studies have not been widely conducted in nonspecialized laboratories, making its utility within a routine primary care setting unproven. Moreover, use of the test for confirming post-treatment eradication looks promising but requires further validation, especially in community-based settings. The use of PPIs may lead to false negative results. In children, low rates of $\mathrm{H}$ pylori infection in Canada would further compromise results, even if the test is performed optimally.

The CHSG considered the argument that the stool antigen test is superior to serology, when performed accurately. The rates of sensitivity and specificity for serology typically range between $75 \%$ and $85 \%$. As the prevalence of $H$ pylori infection falls towards the Canadian level of $30 \%$, the predictive value of serology becomes less reliable. For this reason, serology was not considered to be accurate in many Canadian populations, particularly among individuals younger than 40 years of age. However, the limited diagnostic utility of serology is not a valid justification for promoting the stool antigen test, until its accuracy is confirmed when it is employed as a routine laboratory test.

The evidence that the stool antigen test is accurate under carefully controlled conditions suggests that this method of diagnosis has promise. However, the absence of sufficient evidence of accuracy outside of controlled studies is the reason that this test cannot be recommended as an alternative to UBT at the current time. In Canada, serology, despite its high false positive rate in young individuals, continues to be widely used. The UBT remains the diagnostic method of first choice in adults when endoscopy is not required for other reasons. There is an office-based stool card using the ELISA principle which takes $3 \mathrm{~min}$ to $5 \mathrm{~min}$ to perform, that is currently being examined. In the future, monoclonal antibody-based ELISA tests may prove to be more accurate. Potentially, polymerase chain reaction-based stool antigen testing may be more sensitive than the ELISA-based tests.

\section{RECOMMENDATION 5}

Routine testing for $\mathrm{H}$ pylori infection is not required before initiating long-term therapy with PPIs.
Summary of vote on recommendation

- $A=0$

- $\mathrm{B}=18$

- $\mathrm{C}=6$

- $\mathrm{D}=1$

- $\mathrm{E}=0$

Summary of vote on quality of evidence

- $\mathrm{I}=12$

- $\mathrm{II}-1=0$

- $\mathrm{II}-2=2$

- $\mathrm{II}-3=7$

- $\mathrm{III}=6$

Summary of vote on data supportive of the recommendation

- $\mathrm{A}=0$

- $\mathrm{B}=19$

- $\mathrm{C}=7$

- $\mathrm{D}, \mathrm{E}=\mathrm{O}$

Discussion of recommendation 5

The relationship between chronic PPI therapy, H pylori infection and the progression of gastritis remains incompletely characterized. There is still conflicting evidence as to whether chronic PPI therapy truly does lead to atrophic gastritis in $H$ pylori-positive patients (36). There is convincing evidence that chronic PPI therapy does change the pattern of gastritis in patients who are infected with $\mathrm{H}$ pylori, with worsening and progression of the gastritis in the body of the stomach. The pertinent questions are: does PPI use increase the long-term risk of atrophic gastritis and especially gastric cancer; and does the eradication of $H$ pylori infection alter the possible risks associated with chronic PPI therapy?

The arguments in support of testing for $\mathrm{H}$ pylori infection and treating if positive before starting chronic PPI therapy is that body gastritis does not progress and may even return to normal if $\mathrm{H}$ pylori is eradicated. Specifically, eradication of the infection would be expected to eliminate the risk of $\mathrm{H}$ pylorirelated diseases, including peptic ulcer disease and, potentially, gastric cancers.

Differences in baseline patterns of gastritis and $\mathrm{H}$ pylori infection may account for some of the observed differences, particularly in acid output. When $H$ pylori is eradicated in those with an antral-predominant gastritis, which is characteristic of those with duodenal ulcer disease, gastrin levels typically fall, thereby reducing basal acid secretion. Conversely, in individuals with colonization of the corpus gastritis, eradication of $\mathrm{H}$ pylori infection heals the existing gastritis and will prevent progression. It is uncertain whether atopic gastritis, if present, will revert back to normal $(37,38)$. The more important question is whether regression of body gastritis will decrease the risk of gastric cancer.

The single most important concern regarding the relationship between $H$ pylori infection and chronic PPI therapy is the 
potential for an interaction that increases the risk for the development of gastric cancer. PPI therapy does alter gastric acidity, a variable that affects patterns of $H$ pylori colonization. Typically, lower gastric acidity favours $H$ pylori survival in the corpus, with a related increase in the extent and severity of gastritis. Speculation that these changes set the stage for the development of malignancy remains unsubstantiated. However, some continuing speculation on the conflicting data was the source of dissention in achieving consensus on this recommendation. Importantly, to date there is no evidence that long term use of PPIs or $\mathrm{H}_{2}$ blockers increases gastric cancer risk if $\mathrm{H}$ pylori is present.

On the basis of available data, there is no compelling argument to be made for determining $H$ pylori status in this specific setting. In patients with known $H$ pylori infection, the theoretical benefits of preventing a worsening in gastritis provide a rationale for eradication. However, in patients for whom $H$ pylori status is unknown, the objective evidence to support a policy of testing and treating is not yet available.

\section{RECOMMENDATION 6}

A 'test and treat' strategy for $\mathrm{H}$ pylori infection remains a more cost-effective strategy relative to a trial of PPI therapy in patients with uninvestigated dyspepsia.

\section{Summary of vote on recommendation \\ - $\mathrm{A}=19$ \\ - $\mathrm{B}=12$ \\ - $\mathrm{C}, \mathrm{D}, \mathrm{E}=\mathrm{O}$}

Summary of vote on level of evidence

- $\mathrm{I}=0$

- II $-1=29$

- $\mathrm{II}-2$ to $\mathrm{III}=0$

Summary of vote on data supportive of recommendation

- $\mathrm{A}=0$

- $\mathrm{B}=31$

- $\mathrm{C}, \mathrm{D}, \mathrm{E}=\mathrm{O}$

\section{Discussion of recommendation 6}

Dyspepsia is a common clinical problem. In Canada, 29\% of respondents in a population-based survey reported moderate, persistent or recurrent dyspepsia (39). Indeed, only $34 \%$ reported never having experienced dyspepsia. Due to the frequency of this complaint, cost-effective methods of management are essential, especially in the subgroup of patients who consult their family physician because of chronic symptoms. With nonheartburn-dominant dyspepsia, a strategy of test and treat for $H$ pylori infection was previously endorsed by the CHSG, on the basis of evidence for improvement of symptoms and favourable cost-effectiveness relative to alternative strategies. However, members of the CHSG appreciate that as the prevalence of $\mathrm{H}$ pylori infection declines in Canada and elsewhere, the cost of each positive diagnostic test increases, just as the likelihood that dyspepsia is $H$ pylori-related declines.
Other variables, such as the costs of testing and alternative diagnostic methods, also impact on calculations designed to identify the most rational approach to diagnosis. As a result, it is essential to periodically recalculate the expected yield as well as the expected relative costs of different diagnostic strategies.

Two recently published studies $(40,41)$ have confirmed that the test and treat strategy improves symptoms in individuals with uninvestigated dyspepsia after heartburn as the predominant symptom when the use of NSAIDs has been excluded. However, neither of these studies provided evidence that the test and treat strategy was cost-effective compared with a PPI first strategy for all patients. The Canadian CanDys study group supported the test and treat approach in carefully selected patients with dyspepsia (42). The Canadian Adult Dyspepsia Empiric Treatment-H pylori-positive (CADET-Hp) study (40) demonstrated definite benefit using of test and treat, where the prevalence of $\mathrm{H}$ pylori infection in the population was approximately 20\%, a level that may not be met by younger patients in certain parts of Canada. In a non-Canadian randomized, controlled trial (41), the test and treat strategy resulted in a higher rate of symptom resolution over time than did a trial of PPI therapy. In this latter study, however, the incidence of duodenal ulcers in the target population was $16 \%$, a rate substantially greater than that currently observed in Canada.

The diversity of causes of dyspepsia makes individualization of diagnostic strategies appropriate. Heartburn is not always readily distinguished from other forms of upper gastrointestinal pain or discomfort. Furthermore, most patients have overlapping symptoms, of which heartburn constitutes just one symptom. Whereas a trial of PPI is highly sensitive and specific for identifying symptoms that are acid-related, a strategy of test and treat for $H$ pylori infection remains a viable and cost-effective tool for the control of uninvestigated dyspepsia in patients without alarm symptoms (43).

\section{CONCLUSIONS}

Optimal management of $\mathrm{H}$ pylori infection is evolving. The need for redefinition of previous guidelines is propelled both by new information regarding the relationship between this bacterium and the human host, and also by evolving patterns of $H$ pylori infection and upper gastrointestinal disorders. In Canada, the prevalence of $H$ pylori infection seems to be diminishing along with the disease outcomes, such as peptic ulcer, with which it is associated. However, the extent of a prevalence change has not been studied. The changes are relatively slow and the prevalence of $\mathrm{H}$ pylori infection remains substantial in many parts of Canada, and the potential for serious clinical diseases within infected and potentially infected populations justifies a systematic approach to management. The goal of this update of previously published CHSG recommendations (1-5) is to clarify those areas in which new information has provided the potential for improvements in patient care.

CHSG (Canadian Helicobacter Study Group) - DYSPEPSIA, May 30 to June 1, 2003, Sheraton, Ottawa. Participants: Dr David Armstrong, Dr Alan Barkun, Ms Margaret Boland, Mr Ted Bosworth, Dr Raymond Bourdages, Dr Ron Bridges, Dr Alison Buchan, Dr Ford Bursey, Dr Hugh Chaun, Dr Naoki Chiba, Ms Janet Chlebo, Dr Geraldine Cooper, Dr Brian Craig, Dr Colette Deslandres, Dr Rebekah DeVinney, Mr Lonny Erickson, Dr Carlo Fallone, Dr Lori Fischbach, Dr Nigel Flook, Dr Krishnasamy Govender, Dr Richard Hunt, 
Dr Kevan Jacobson, Dr Nicola Jones, Ms Sylvia Klompus, Ms Nathalie Leduc, Dr Frank Lin, Dr Jacob Louw, Dr Richard McCammon, Dr Jon Meddings, Ms Krista Nevin, Dr Garth Noad, Dr Terry Ponich, Dr Jamal Serrar, Dr Phil Sherman, Dr Fiona Smaill, Dr Lesley Smith, Ms Wendy Smith, Dr Jean Spenard, Dr Markus Stein, Dr Cathy Streutker, Dr Alan Thomson, Dr Peter Thomson, Dr Sander Veldhuyzen vanZanten, Dr Scott Whittaker, Dr Noel Williams, Dr Robert Woodland.

\section{REFERENCES}

1. Hunt R, Thomson AB. Canadian Helicobacter pylori consensus conference. Canadian Association of Gastroenterology. Can J Gastroenterol 1998;12:31-41.

2. Hunt RH, Fallone CA, Thomson ABR. Canadian Helicobacter pylori Consensus Conference update: Infections in adults. Canadian Helicobacter Study Group. Can J Gastroenterol 1999;13:213-7.

3. Sherman P, Hassall E, Hunt RH, Fallone CA, Veldhuyzen van Zanten S, Thomson AB. Canadian Helicobacter Study Group Consensus Conference on the Approach to Helicobacter pylori Infection in Children and Adolescents. Can J Gastroenterol 1999;13:553-9.

4. Hunt RH, Smaill FM, Fallone CA, Sherman PM, Veldhuyzen van Zanten SJ, Thomson AB. Implications of antibiotic resistance in the management of Helicobacter pylori infection: Canadian Helicobacter Study Group. Can J Gastroenterol 2000;14:862-8.

5. Hunt RH, Fallone C, Veldhuyzen van Zanten S, et al, for the Canadian Helicobacter Study Group. Etiology of dyspepsia: Implications for empirical therapy. Can J Gastroenterol 2002;16:635-41.

6. Dent J, Brun J, Fendrick AM, et al. An evidence-based appraisal of reflux disease management - The Genval Workshop Report. Gut 1999;44(Suppl 2):S1-S16.

7. Barkun A, Bardou M, Marshall JK. Consensus recommendations for managing patients with nonvariceal upper gastrointestinal bleeding. Ann Intern Med 2003;139:843-57.

8. Warren JR, Marshall BJ. Unidentified curved bacilli on gastric epithelium in active chronic gastritis. Lancet 1983;i:1273-5.

9. Megraud F. Duodenal ulcer disease: A new infectious disease. Eur J Gastroenterol Hepatol 1993;5(Suppl 1):S17-S22.

10. Parsonnet J, Hansen S, Rodriguez L, et al. Helicobacter pylori and gastric lymphoma. N Engl J Med 1994;330:1267-71.

11. Correa P, Haenszel W, Cuello C, Tannenbaum S, Archer M. A model for gastric cancer epidemiology. Lancet 1975;2:58-60.

12. Gene E, Calvet X, Azagra R, Gisbert JP. Triple vs quadruple therapy for treating Helicobacter pylori infection: A meta-analysis. Aliment Pharmacol Ther 2003;17:1137-43.

13. Fischbach LA, Goodman KJ, Feldman M, Aragaki C. Sources of variation of Helicobacter pylori treatment success in adults worldwide: A meta-analysis. Int J Epidemiol 2002;31:128-39.

14. Harris A. Hitting $H$ pylori for four. Lancet 1995;345:806-7.

15. Calam J. Clinicians' Guide to Helicobacter pylori. London: Chapman \& Hall, 1996

16. Laine L, Hunt R, El-Zimaity H, Nguyen B, Osato M, Spenard J. Bismuth-based quadruple therapy using a single capsule of bismuth biskalcitrate, metronidazole, and tetracycline given with omeprazole versus omeprazole, amoxicillin, and clarithroymycin for eradication of Helicobacter pylori in duodenal ulcer patients: A prospective, randomized, multicenter, North American Trial. Am J Gastroenterol 2003;98:562-7.

17. Basset C, Holton J, Ricci C, et al. Review article: Diagnosis and treatment of Helicobacter: A 2002 updated review. Aliment Pharmacol Ther 2003;17(Suppl 2):89-97.

18. Calvet X, Garcia N, Lopez T, Gisbert JP, Gene E, Roque M. A meta-analysis of short versus long therapy with a proton pump inhibitor, clarithromycin and either metronidazole or amoxycillin for treating Helicobacter pylori infection. Aliment Pharmacol Ther 2000;14:603-9.

19. Fischbach LA, Goodman KJ, Feldman M, Aragaki C. Sources of variation of Helicobacter pylori treatment success in adults worldwide: A meta-analysis. Int J Epidemiol 2002;31:128-39.

20. Vakil N, Perdomo C, Barth J. Clarithromycin resistance and $H$ pylori eradication rates in US racial groups with rabeprazolebased triple therapy. Gastroenterology 2003;124(Suppl 1):A360-1.
21. Best L, Cooper-Lesins G, Haldane D, Spenard J, Fallone C, Veldhyzen van Zanten SJO. Helicobacter pylori antibiotic resistance in Canadian populations. Gastroenterology 2004;126:S1293.

22. Forman D, Webb PM. Helicobacter pylori and gastric cancer: The significance of the problem. In: Hunt RH, Tytgat GNJ, eds. Helicobacter pylori: Basic Mechanisms to Clinical Cure. Lancaster: Kluwer Academic Publishers, 1996;461-8.

23. Kikuchi S, Wada O, Nakajima T, et al. Serum anti-Helicobacter pylori antibody and gastric carcinoma among young adults. Research Group on Prevention of Gastric Carcinoma among Young Adults. Cancer 1995;75:2789-93.

24. Huang JQ, Hunt RH. Review article: Helicobacter pylori and gastric cancer - the clinicians' point of view. Aliment Pharmacol Ther 2000;14(Suppl 3):48-54.

25. Van Grieken NC, Meijer GA, Weiss MM, et al. Quantitative assessment of gastric corpus atrophy in subjects using omeprazole: A randomized follow-up study. Am J Gastroenterol 2001;96:2882-6.

26. Uemura N, Okamoto S, Yamamoto S, et al. Helicobacter pylori infection and the development of gastric cancer. N Engl J Med 2001;345:784-9.

27. Saito K, Arai K, Mori M, Kobayashi R, Ohki I. Effect of Helicobacter pylori eradication on malignant transformation of gastric adenoma. Gastrointest Endosc 2000;52:27-32.

28. Hohenberger P, Gretschel S. Gastric cancer. Lancet 2003;362:305-15.

29. Sung JJ, Lin SR, Ching JY, et al. Atrophy and intestinal metaplasia one year after cure of $H$ pylori infection: A prospective, randomized study. Gastroenterology 2000;119:7-14.

30. Fallone CA, Barkun AN, Halwani F. Does Helicobacter pylori eradication prevent gastric cancer? Dig Liver Dis 2001;33:803-4.

31. Rowland M, Kumar D, Daly K, O'Connor P, Vaughan D, Drumm B. Low rates of Helicobacter pylori reinfection in children. Gastroenterology 1999;117:336-41.

32. Chiba N, Veldhuyzen van Zanten SJO. 13C-Urea breath tests are the noninvasive method of choice for Helicobacter pylori detection. Can J Gastroenterol 1999;13:681-3.

33. Huang JQ, Sridhar S, Hunt RH. Role of Helicobacter pylori infection and non-steroidal anti-inflammatory drugs in peptic-ulcer disease: A meta-analysis. Lancet 2002;359:14-22.

34. Hawkey CJ. Progress in prophylaxis against nonsteroidal antiinflammatory drug-associated ulcers and erosions. Omeprazole NSAID Steering Committee. Am J Med 1998;104:67S-74S.

35. Vaira D, Vakil N. Blood, urine, stool, breath, money, and Helicobacter pylori. Gut 2001;48:287-9.

36. Kokkola A, Sipponen P, Rautelin H, et al. The effect of Helicobacter pylori eradication on the natural course of atrophic gastritis with dysplasia. Aliment Pharmacol Ther 2002;16:515-20.

37. Shenk BE, Kuipers EJ, Nelis GF, et al. Effect of Helicobacter pylori eradication on chronic gastritis during omeprazole therapy. Gut 2000;46:615-21.

38. Kuipers EJ, Nelis GF, Klinkenberg-Knol EC, et al. A cure of Helicobacter pylori infection in patients with reflux oesophagitis treated with long term omeprazole reverses gastritis without exacerbation of reflux disease: Results of a randomized controlled trial. Gut 2004;53:12-20.

39. Tougas G, Chen Y, Hwang P, Liu MM, Eggleston A. Prevalence and impact of upper gastrointestinal symptoms in the Canadian population: Findings from the DIGEST study. Domestic/ International Gastroenterology Surveillance Study. Am J Gastroenterol 1999;94:2845-54.

40. Chiba N, Van Zanten SJ, Sinclair P, Ferguson RA, Escobedo S, Grace E. Treating Helicobacter pylori infection in primary care patient with uninvestigated dyspepsia: The Canadian adult dyspepsia empiric treatment-Helicobacter pylori positive (CADET-Hp) randomised controlled trial. BMJ 2002;324:1012-6.

41. Manes G, Menchise A, de Nucci C, Balzano A. Empirical prescribing for dyspepsia: Randomised controlled trial of test and treat versus omeprazole treatment. BMJ 2003;326:1118-21.

42. Veldhuyzen van Zanten SJO, Flook N, Chiba N, et al, for the Canadian Dyspepsia Working Group. An evidence-based approach to the management of uninvestigated dyspepsia in the era or Helicobacter pylori. CMAJ 2000;162(12 Suppl):S3-S23.

43. Makris N, Barkun A, Crott R, Fallone CA. Cost-effectiveness of alternative approaches in the management of dyspepsia. Int J Tech Assess Health Care 2003;19:446-64. 


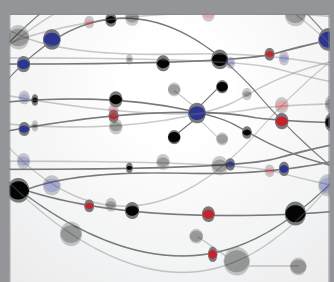

The Scientific World Journal
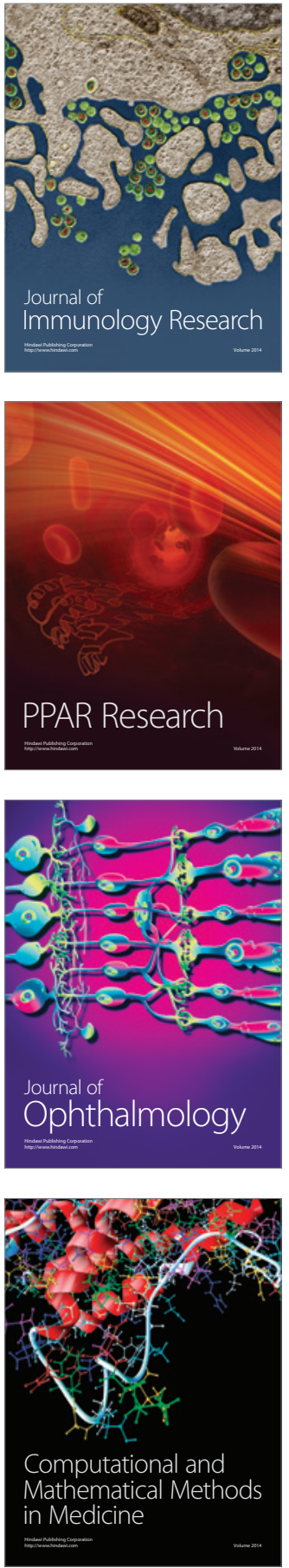

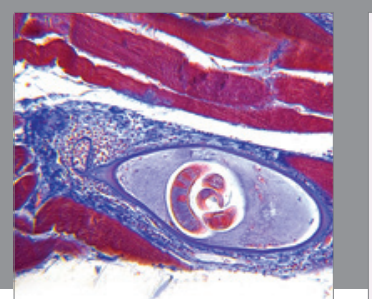

Gastroenterology Research and Practice

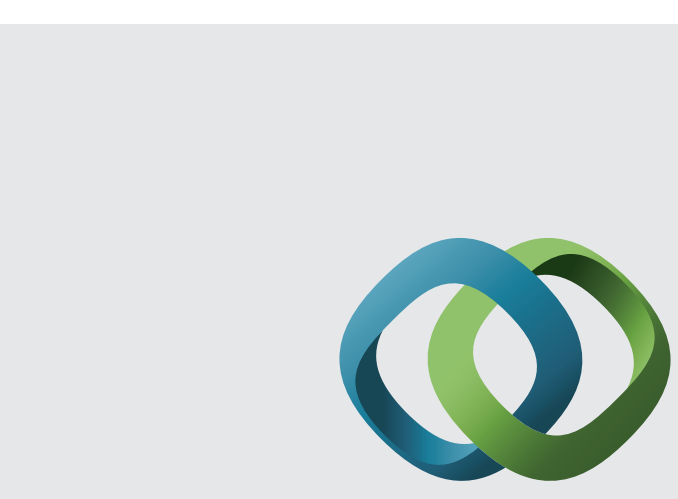

\section{Hindawi}

Submit your manuscripts at

http://www.hindawi.com
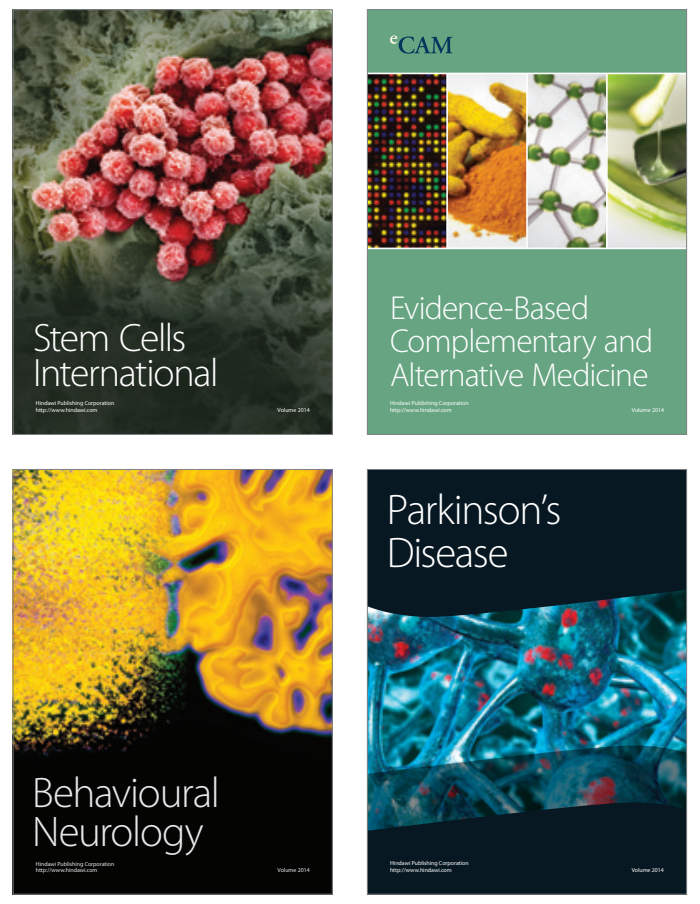
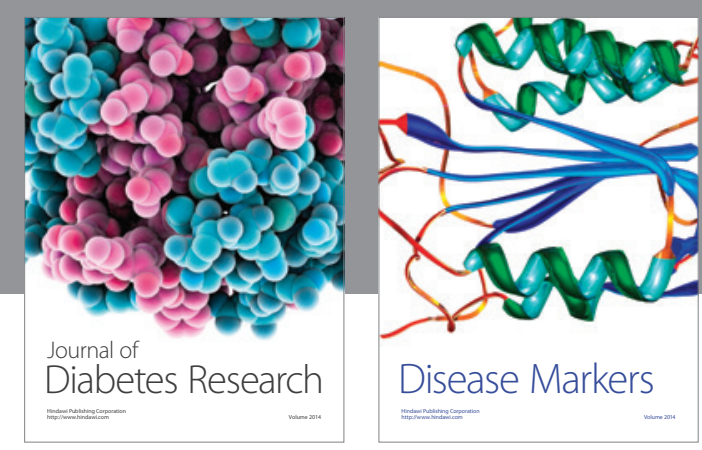

Disease Markers
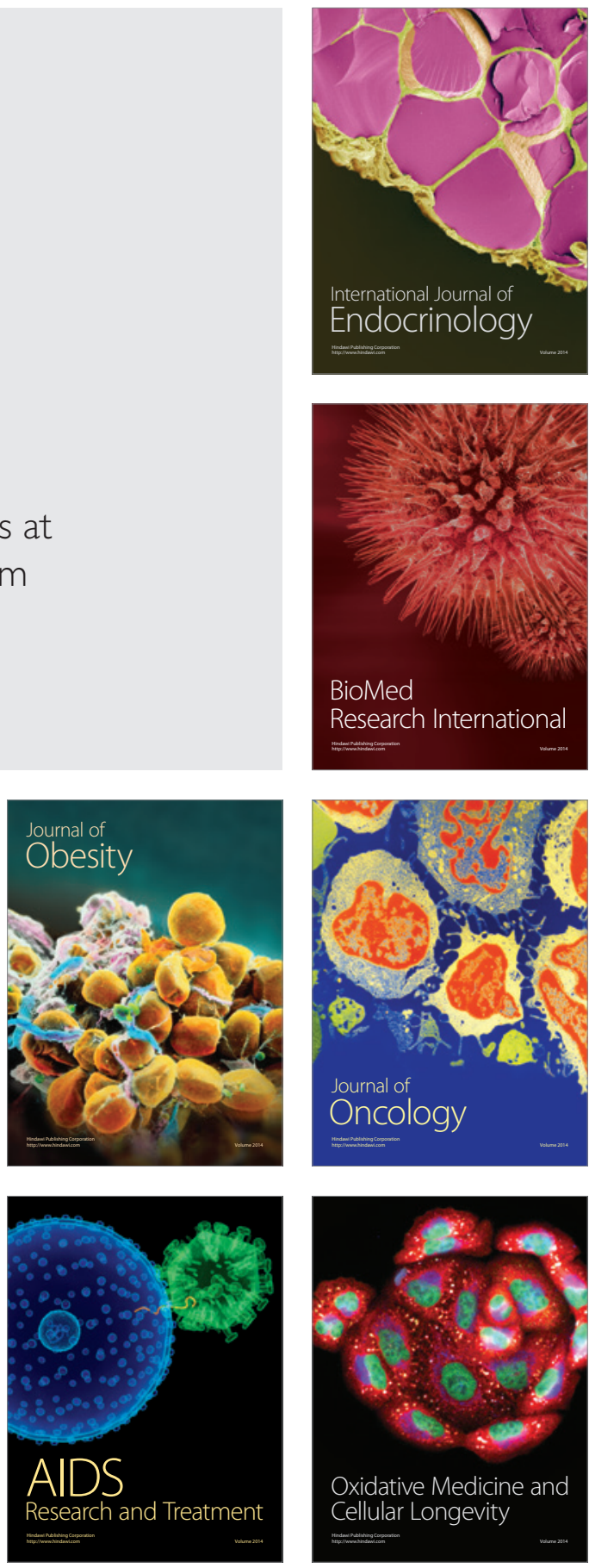